Proc. Indian Acad. Sci. (Earth Planet. Sci.), Vol. 95, No. 2, July 1986, pp. 237-244.

(C) Printed in India.

\title{
Effect of waves in the redistribution of sediments along the Konkan coast
}

\author{
G VICTOR RAJAMANICKAM*, P VETHAMONY and A R GUJAR \\ National Institute of Oceanography, Dona Paula, Goa 403004, India \\ *Dapartment of Ancient Industries, Tamil University, Tanjavur 613001, India \\ MS received 8 July 1985 ; revised 14 March 1986
}

\begin{abstract}
From the wave refraction diagrams it is delineated that the Jaigad Head and Warori Bluff are the zones of wave energy convergence and the Narvan and Ambwah bays the areas of wave energy divergence. The presence of two distinct mineral phases noticed at the Jaigad, Ambwah and Varvade bays shows that there are two different circulations of sediment movements. The presence of natural barriers restricts the movement of sediment along the coast. The sand bar at the mouth of the Jaigad Bay has different orientations during the monsoon and non-monsoon periods causing obstruction to navigation during the former period.
\end{abstract}

Keywords. Konkan coast; erosion; accretion; sediment movement; natural barriers; sand bar.

\section{Introduction}

Wave action is the primary source of energy available in the nearshore zones for various processes responsible for sediment motion along any open coast. Depending upon the configuration of the coastal line, nature of the wind, tide and several other factors, there is a possibility of waves being modified to increase or to dissipate their energy, in any particular coastal region. The area under study is affected by waves with short periods and high amplitudes during the monsoon season from June to October, whereas the low swells prevail from October to May. Further, these waves break offshore, widening the surf zone and setting more sand in motion. The wave velocity depends on the depth, and as the wave approaches the coast, it undergoes 'wave refraction'. As a result of refraction the waves tend to become parallel with the coast where they break at a slight angle to the coast. The long shore compound of wave energy gives rise to littoral currents in the surf zone contributing dominantly to the movement of the nearshore sediments. The angle between the crest of the breaking wave and the shoreline determines the direction of the long-shore component of water motion in the surf zone and also the long-shore transport direction. One of the important effects of littoral currents is the movement of sands as littoral drift along the coast. Moni (1972) calculated the quantum of the gross littoral drift along the west coast of India to be about 1.25 million cubic meters per annum.

Knowledge about the wave climate (wave height, period and direction) is necessary for better comprehension of wave action on or near the shore. Shrivastava et al (1968), Moni (1972) and Reddy (1976) indicated from their studies of the west coast of India that the predominant direction of waves in this area is from SW, WSW, W and WNW as in Reddy (1976) with periods ranging from 5 to 14 seconds. The convergence and 
divergence of the littoral currents in several places along the west coast of India were also noted under the action of the WSW and W waves. Wave refraction diagrams indicate the zones of divergence and convergence of waves, which are directly related to the sediment motion in the nearshore area. The relationship between wave characteristics and sediment movement in various localities has been studied by several workers including Sastry (1958) and Murthy (1977).

\section{Area of study}

The few bays that have been selected for this study are bounded by a submergent type of coast line on the east, wide Arabian Sea on the west and bounded by cliffs or headlands to the south and north. Within the investigated area (figure 1) are three prominent bays: namely Jaigad, Ambwah and Varvade in which a total area of about $36 \mathrm{~km}^{2}$ was chosen for detailed sampling in connection with the placer mineral exploration. The bays have a crenellated coastline with narrow sandy beaches. Sometimes along the headlands there are rocky boulders and pockets of coarse sandy beaches (figure 2). Although there are a number of small rivers/creeks draining into these bays, nowhere is formation of estuaries noticed. Instead, small tidal inlets are seen. Small bars and spits are present in almost all the bays, obstructing navigation during low tide periods and completely closing the seaward opening of the bays during the monsoon months.

\subsection{Description of the bays}

During field work, a perceptible shift in the coastline, as compared to the one shown in the Admiralty chart in 1950, was noted and hence the re-surveyed coast line is presented here (figure 1). Inasmuch as the coastline from Jaigad to Varvade is very irregular and indented, it has become quite long. The presence of rocky terraces, headlands, numerous cliffs and rias made Ahmed (1972) classify this coastline as of the submergent type. Barring the northern part of the Jaigad Bay and also the Varvade Bay, this coastline is completely devoid of straight sandy beaches. The existing few short seasonal streams and creeks originating in the nearby basaltic cliffs, are characterised by their steep gradient, deep cut V-shaped valleys, and bed load of pebbly and bouldery material. Well formed wave cut terraces are exposed during low tide in some of the head lands.

Although quite a large number of rivers and streams drain the area, the Shastri and Varvade rivers are worth mentioning and they join the sea obliquely to the coastline without affording any opportunity for estuarine formation. However, they cause the development of tidal inlets, whose presence can be marked by sandbars in the Shastri river confluence and also by a small shoal in the Varvade creek mouth. Despite the hilly terrain with very few pockets of coastal plain and beach, many tidal inlets do exist. These inlets get flooded during high tides resulting in the formation of swamps and mangroves, particularly in the Nandivade, Ambwah and Varvade areas. Besides the above, littoral concrete, which is a rocky beach, also occurs in a few places along this coast.

The coastline, which is flanked by flat topped hills and headlands, is indented by a number of arcuate bays. For the purpose of presenting the physiographic and 


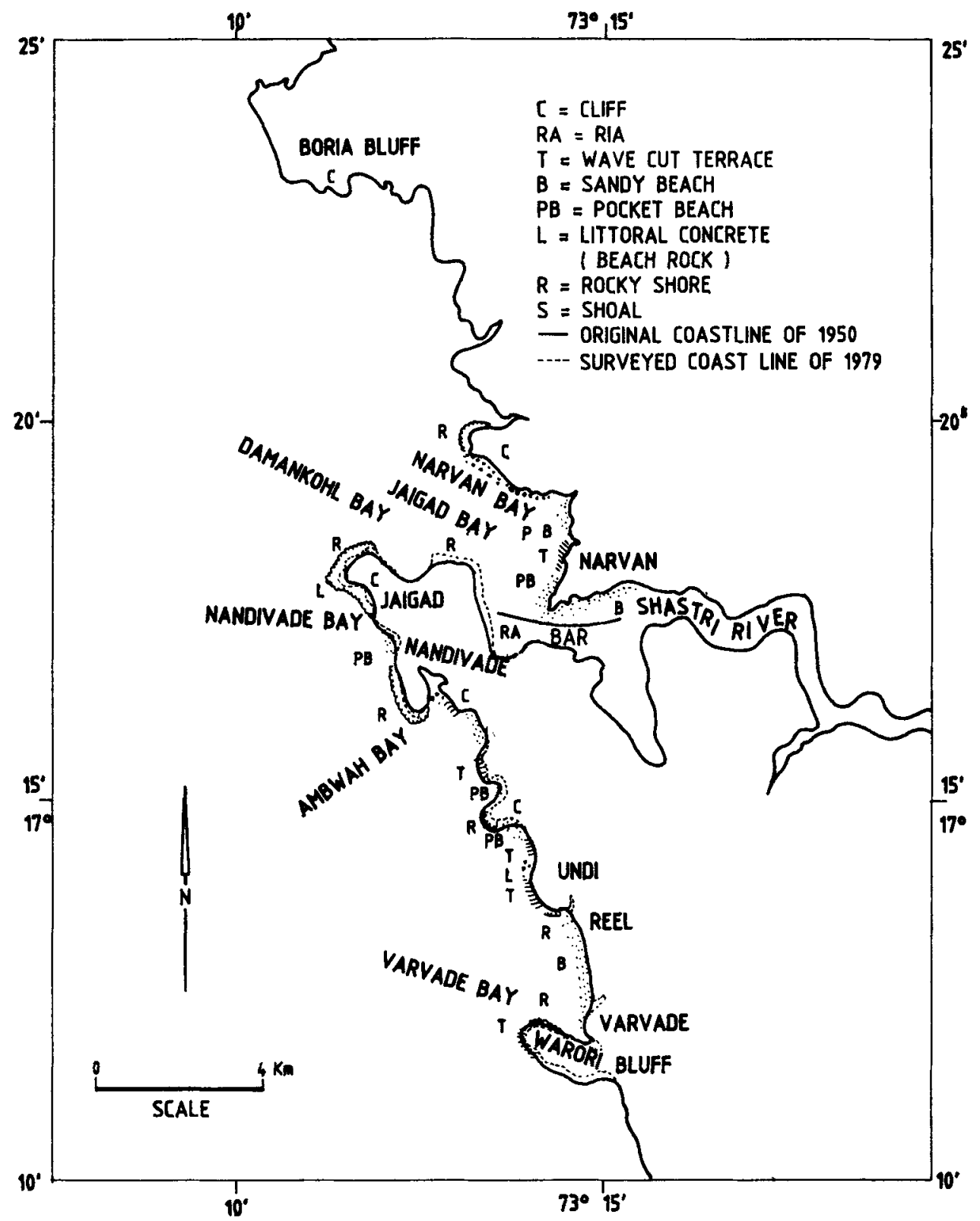

Figure 1. Coastline features (modified after Ahmed, 1972).

oceanographic data, these bays are grouped under three heads: viz., (1) the Jaigad Bay, which is a protected bay, is flanked by the Jaigad headland and the Boria bluff and it receives a large quantity of sediment influx from the Shastri river and is subject to the effect of waves. (2) The Varvade Bay having limited protection by the Warori Bluff, is exposed only to a weak tidal inlet and receives very limited sediment supply, while (3) the Ambwah Bay, which has primarily an open sea coast, is neither influenced by tidal inlets nor by sediment supply. 


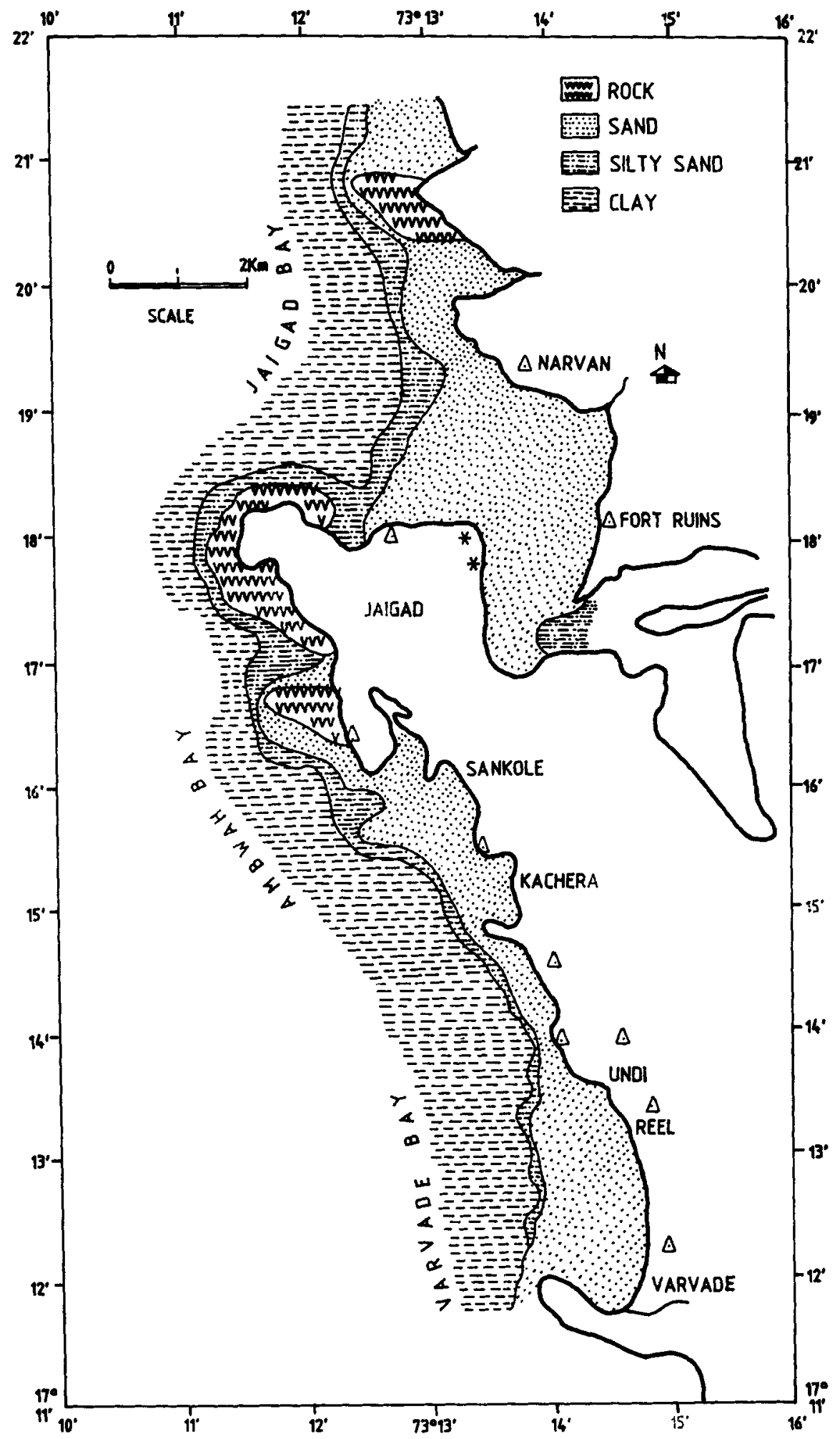

Figure 2. Distribution of sediments. 


\section{Method of study}

Wave refraction studies can be done either by graphical or numerical methods. Harrison and Wilson (1964) have opined that the numerical method is comparatively more accurate and less time consuming and it has been employed in the present study, for which a programme developed by Mahadevan and Radhiya (1983) and applied at the National Institute of Oceanography, has been used. Common assumptions as included in the Shore Protection Manual (Anon 1977) for wave refraction calculations, have been adopted. Water depth, wave period, and deep water wave direction are the three major input parameters. The offshore area, starting from $200 \mathrm{~m}$ water depth is divided into 1.25 inch square grids. The interpolated depths from the hydrographic chart at the intersection points of the grid lines are taken for the purpose of input depth. The starting depth of each orthogonal (wave ray) is always maintained at half the wave length. Based on the report of Reddy (1976), the wave periods 6, 8, 10 and 12 seconds, and wave directions SW, WSW, W and WNW have been taken into consideration for computations on the Institute's computer TDC 316. Over and above, the effects of the presence of natural barriers in the form of headlands, and the observed sand bar and the shoal in front of the river confluences have also been taken note of in the interpretation of sediment movement.

\section{Results and discussion}

An examination of the wave refraction diagrams (figure 3) shows that the waves approaching this part of the coastline from WNW to SW in deep water converge in the neighbourhood of Jaigad. The inner portion of the Jaigad Bay forms a wave shadow zone for waves coming from $\mathrm{SW}$ to $\mathrm{W}$ which are the dominant directions in the $\mathrm{SW}$ monsoon period. The overall results indicate that: (1) the Jaigad Head and the Warori Bluff are wave converging points while the northern part of Jaigad or Narvan and Ambwah bays are the places of wave divergence. Because of the convergence of wave energy near the Jaigad Head and the Warori Bluff, removal of sediments, especially lighter materials takes place. This conclusion is also supported by the presence of a rocky beach, as well as a rocky seabed, even upto a depth of $10 \mathrm{~m}$ in front of these promontories. In the clay whatever silt remains is made up of only high specific gravity materials like magnetite and ilmenite; (2) On the contrary, along the coasts of Ambwah and Narvan, the divergence of wave rays indicate reduced wave activity and, consequently, deposition. The deposition is also substantiated by the nature of sediments i.e. the sediments containing rich plant materials and light fractions like quartz and felspars.

In addition, it is also observed that there is no sediment transport either from the Varvade to the Jaigad Bay or vice-versa because the heavy mineral assemblages reported by Rajamanickam (1983) indicate enrichment in two distinct mineral phases of olivine and pyroxene in the Jaigad Bay, and tourmaline-zircon-kyanite in the Ambwah and Varvade bays. It is observed that the Jaigad Bay sediments have redcoloured ferruginous coating, while the sediments of the other two bays are made up of crystal clear grains. It is a case of clear zonation of two different circulations of sediment movements within the studied area, viz., one circulation from the Shastri river confluence at the Narvan Bay to the Boria Bluff and back to the Jaigad Bay, and the 

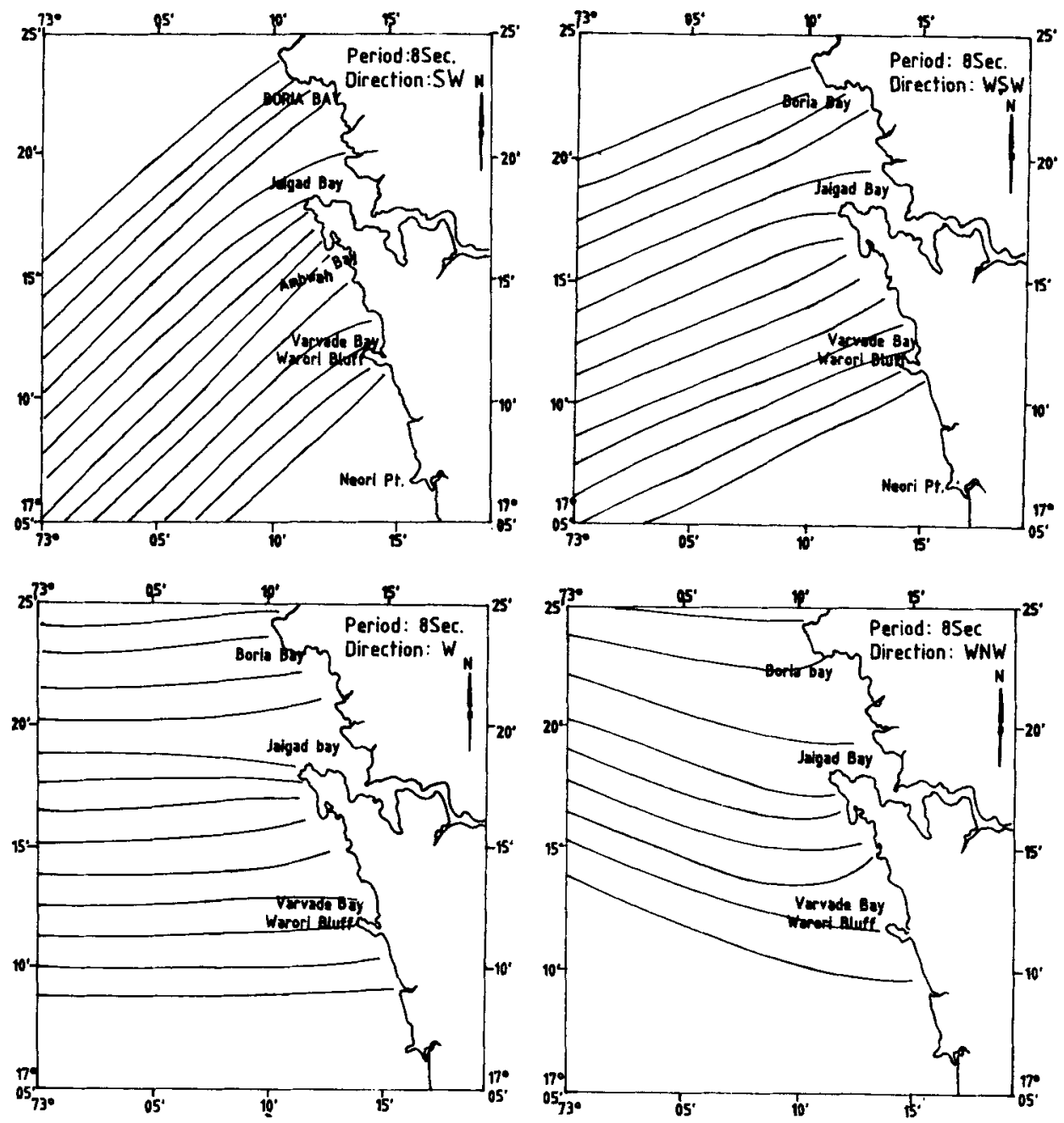

Figure 3. Wave refraction diagrams for different wave directions.

other from Varvade to Ambwah, and to some extent to Nandivade, and back. There is no sedimentation in front of the Jaigad Head but for fine silty-clay adjacent to the rocky seabed. Such circulations have also been observed between the promontories in other parts of the west coast of India by Veerayya et al (1981).

Nevertheless, the presence of distinct promontories might have also aided the restrictions caused by the convergence because if an artificial or a natural barrier is present perpendicular to a straight beach, contrary effects will be observed even with the same direction of incident wave according to the size of the material, wave energy, length of the barrier etc (LeMahaute and Brebner 1961). In such a case, there will be accretion on the updrift side and erosion on the downdrift side. In the present case, the Jaigad Head and the Warori and Boria Bluffs are natural barriers affecting the littoral drift considerably.

The Warori Bluff extends upto a water depth of $9 \mathrm{~m}$ while the Jaigad Head projects 
upto $11 \mathrm{~m}$ water depth. Generally, $9 \mathrm{~m}$ is considered to be the optimum depth of water for the conduction of coastal processes (LeMahaute and Soldate 1978). Due to the presence of natural barriers the coast immediately to the south of the Jaigad Head (Ambwah Bay) and south of the Boria Bluff (Narvan Bay) experiences deposition of sediments, whereas the coast on the northern side undergoes erosion. Similarly, Varvade Bay, situated in the northern part of the Warori Bluff shows erosion. Such erosions are found to remove mainly the light minerals and flaky constituents. Hence, the presence of enriched heavy minerals in the Varvade Bay and finer heavy minerals together with coarse lighter minerals in the Jaigad Bay might have occurred due to such erosion. The lighter material removed from the Varvade Bay is deposited in the Ambwah bay (south of the Jaigad Head), which is relatively enriched in this type of sediment. Likewise, the north of the Jaigad head suffers erosion by losing light minerals along with fine heavier material, but both of similar hydraulic equivalent, and the same is deposited in the northern part of the Narvan Bay due to the presence of the Boria Bluff in the north. There are two inlets in the area, one in the mouth of the Varvade Creek and the other in the Shastri River mouth, which has a sand bar constituted of coarse black sand formed parallel to the coast of the Narvan Headland. During the southwest monsoon months (June-October) the bar shifts slowly and attains a change in its orientation becoming almost perpendicular to the coast. At this stage, the bar is fully submerged whereas once it shifts and becomes parallel to the shore, it is clearly exposed during low tide. During monsoon/non-monsoon seasons the orientation of the bar shifts in accordance with the relative higher effectiveness of either wave activity or river runoff. On the other hand, the other inlet at the Varvade Creek mouth is associated with a shoal made of medium grained shelly sand at $10 \mathrm{~m}$ water depth extending from the northern bank of the channel to about $300 \mathrm{~m}$ parallel to the shore and rising to about $3-4 \mathrm{~m}$.

When an offshore bar has been built up sufficiently high, breakers sweeping over the crest of the bar, transfer bar material from the seaward face causing the migration of the bar landwards. If the influence of waves is reduced, bar deformations are determined by means of river run-off. The Jaigad Head is a zone of erosion. The formation of a bar (if any) at the inlet and its orientation are also important parameters to consider wherever erosion occurs. The inlet at the Shastri river mouth acts as the sand sink to absorb sand coming from the Jaigad Head and to a certain extent from the Narvan Coast due to WNW waves.

If the natural barrier were not formed, the northerly longshore current would have fed sediment to the bay. Since only sand is observed in the bay as well as in the bar, there is every possibility of its derivation from the adjacent coast. Part of the material which is fed to the inlet is taken away by the ebb flow causing the bar to grow (Walton and Adams 1976). The river discharge is unable to wash out the sand accumulation, which slowly moves to block the navigational channel, specially during the monsoon months in which wave action is considerable.

Dean and Walton (1975) stated that the seaward transport of sand is due to tidal currents, whereas the landward movement of sand is probably due to wave forces. Since the channel is close to the natural barrier, no material is transported inside due to the strong erosion taking place, which is substantiated by the presence of a non-scouring hard rock bottom at the channel. Since the bar is formed in the wave divergence zones, it becomes a permanent feature and acts as a barrier for the mixing of river sediments with the bay. 


\title{
5. Conclusions
}

This study has revealed the presence of two strong wave convergent points at the Jaigad Head and the Warori Bluff, wherein the bays north of the above convergent zones, i.e. the northern parts of the Jaigad and Ambwah bays, are seen as wave divergence zones. This is also supplemented by the deposition of higher amounts of lighter minerals. In addition to the above wave refraction effects, the presence of natural barriers like the Jaigad Head, and the Warori and Boria Bluffs, contribute appreciably to restricting the littoral sediment movement among the bays. The presence of a sand bar and a shoal in front of the Shastri River and the Varvade Creek mouth, respectively, are considered to be the result of obstruction to the free mixing of the incoming sediments with the bay sediments. The overall heavy mineral percentage distribution within the three bays are the result of wave refraction, physical barriers and the presence of a sand bar shoal.

\section{Acknowledgements}

The authors thank Dr. H N Siddiquie and Prof O P Varma for encouragement and guidance, Dr J S Sastry for suggestions and Dr R Mahadevan and P Chandramohan for assistance. A part of this work was carried out at the Indian School of Mines, Dhanbad, during the course of the first author's doctoral study.

\section{References}

\author{
Ahmed E 1972 Coastal Geomorphology of India (Bombay: Orient Longman) \\ Anon 1977 Shore protection manual (Army Coastal Eng. Center: US Govt. Press) \\ Dean R G and Walton T L 1975 Proc. 2nd Int. Estu. Res. Fed. Conf. (Myrtle Beach) \\ Harrison W and Wilson W S 1964 TM-6. US Army Corps of Engineers CERC, Washington DC \\ LeMahaute B and Brebner B 1961 An Introduction to coastal morphology and littoral processes CERC US \\ Report \\ LeMahaute B and Soldate M 1978 Proc. of Coastal Eng. Conf. ASCE, New York \\ Mahadevan R and Radhiya P S R 1983 Proc 2nd Ind. Conf in Ocean Eng., Vol 1 \\ Moni N S 1972 Proc. of Coastal Eng. Conf., ASCE, New York \\ Murthy C S 1977 Studies on the physical aspects of shoreline dynamics at some selected places along the west \\ coast of India Ph. D. thesis Andhra University \\ Rajamanickam G V 1983 Geological investigations of offshore heavy mineral placers of Konkan Coast, \\ Maharashtra, India Ph. D. thesis, submitted to Indian School of Mines, Dhanbad \\ Reddy M P M 1976 Indian J. Mar. Sci. 5, 152 \\ Sastry $\mathrm{J} S 1958$ Some aspects of shoreline process and physical oceanography $\mathrm{Ph}$. D. thesis, Andhra University \\ Shrivastava P S, Nair D K and Ramankartha K R 1968 Indian J. Meteorol. Geophys.19, 329 \\ Veerayya M V, Murthy C S and Varadachari V V R 1981 Indian J.Mar.Sci. 101 \\ Walton T L Jr and Adams W D 1976 Proc. of Coastal Engg. Conf., ASCE, New York
}

